\title{
Prevalence and risk factors associated with sexually transmitted infections (STIs) among women of reproductive age in Swaziland
}

Themba G. Ginindza ${ }^{*}$, Cristina D. Stefan ${ }^{2}$, Joyce M. Tsoka-Gwegweni ${ }^{1}$, Xolisile Dlamini ${ }^{3}$, Pauline E. Jolly ${ }^{4}$, Elisabete Weiderpass ${ }^{5,6,7,8}$, Nathalie Broutet ${ }^{9}$ and Benn Sartorius ${ }^{1}$

\begin{abstract}
Background: Sexually transmitted infections (STIs) remain an important public health problem with approximately half a billion new cases annually among persons aged 15-49 years. Epidemiological data on STIs among women of reproductive age in Swaziland are limited. The availability of epidemiological data on STIs and associated risk factors in this population is essential for the development of successful prevention, diagnosis and management strategies in the country. The study aimed to determine the prevalence and risk factors associated with STIs.

Methods: A total of 655 women aged 15-49 years were systematically enrolled from five health facilities using a cross-sectional study design. Cervical specimen were tested using GeneXpert CT/NG Assays for Chlamydia trachomatis (CT) and Neisseria gonorrhoeae (NG), GeneXpertTV Assay for Trichomonas vaginalis (TV), and GeneXpert HPV Assays for hr-HPV. Blood samples were tested using Alere Determine HIV-1/2Ag/Ab Combo and Trinity Biotech Uni-Gold Recombigen HIV test for confirmation for HIV, and Rapid Plasma Reagin and TPHA test for confirmation for Treponema pallidum (syphilis). Genital warts were assessed prior to specimen collection. Survey weighted analyses were done to estimate the population burden of STIs.
\end{abstract}

Results: The four most common curable STIs: CT, NG, TV, Treponema pallidum (syphilis), as well as genital warts were considered in this study. The overall weighted prevalence of any of these five STIs was 19.4\% (95\% Cl: 14.9-24.8), corresponding to 72990 women with STIs in Swaziland. The estimated prevalences were 7.0\% (95\% Cl: 4.1-11.2) for CT, 6. 0\% (95\% Cl: 3.8-8.8) for NG, 8.4\% (95\% Cl: 5.4-12.8) for TV, 1.4\% (95\% Cl: 1.1-10.2) for syphilis and 2.0\% (95\% Cl: 1.0-11.4) for genital warts. The overall weighted HIV prevalence was 42.7\% (95\%Cl: 35.7-46.2). Among hr-HPV positive women, 18. 8\% (95\% Cl: 13.1-26.3) had one STI, while 6.3\% (95\% Cl: 3.3-11.7) had multiple STIs. Risk factors associated with STls were being employed ( $\mathrm{OR}=2.2,95 \% \mathrm{Cl}: 1.0-4.7)$, self-employed ( $\mathrm{OR}=2.8,95 \% \mathrm{Cl}: 1.5-5.5)$ and being hr-HPV positive (OR=2.0, $95 \%$ Cl: $1.3-3.1)$. Age $(0.9,95 \%$ Cl: $0.8-0.9)$, being married $(\mathrm{OR}=0.4,95 \% \mathrm{Cl}: 0.3-0.7)$ and not using condoms with regular partners (OR=0.5, 95\% Cl: 0.3-0.9) were inversely associated with STls.

Conclusion: STIs are highly prevalent among women of reproductive age in Swaziland. Thus, a comprehensive STIs screening, surveillance and treatment programme would be justified and could potentially lower the burden of STIs in the country.

Keywords: Sexually transmitted infections, HIV, HPV, Risk factors, Mbabane, Swaziland, Epidemiology, Women, Cross sectional study, Africa

\footnotetext{
*Correspondence: Ginindza@ukzn.ac.za

${ }^{1}$ Discipline of Public Health, School of Nursing and Public Health, University of KwaZulu-Natal, 2nd Floor George Campbell Building, Mazisi Kunene Road, 4041 Durban, South Africa

Full list of author information is available at the end of the article
} 


\section{Background}

Globally, sexually transmitted infections (STIs) remain a significant public health problem mainly in low-income countries [1, 2]. Currently, approximately half a billion new cases occur worldwide each year [3], and more than one million STIs are acquired per day [4]. Of the estimated total of 357 million incident cases of the curable STIs world-wide, 131 million are from Chlamydia trachomatis (CT), 78 million are from Neisseria gonorrhea (NG), 5.6 million are from syphilis and 143 million are from Trichomonas vaginalis (TV) cases [3, 4]. The World Health Organization (WHO) further estimated that 8.3, 21.1 and 59.7 million new cases of CT, NG and TV infections respectively, occur in sub-Saharan Africa (SSA), with the majority of new STIs occurring among the population aged 15 to 49 years [5].

Depending on which STI and the population, in lowincome countries largely in SSA, NG, CT, TV, Human papillomavirus (HPV), herpes, and syphilis increase the risk of HIV acquisition and transmission between two to eight fold [4, 6-9]. Furthermore, the inflammation resulting from viral and non-viral STIs increases viral shedding of HIV-1 in the genital tract [10-12] and also increases the risk of HIV-1 transmission to the sex partners $[13,14]$. It is estimated that the probability of HIV transmission per sexual contact is $6 \%$ if either partner has another STI other than HIV [15] as compared to $0.2 \%$ in the absence of STIs [16]. The impact of coinfection of HPV with HIV in the SSA has increased the burden of cervical diseases (such as cervical lesions and cancer), since HIV infected women have a higher prevalence of hr-HPV [17]. Furthermore, STIs such as NG and $\mathrm{CT}$ are the major causes of pelvic inflammatory disease (PID) and infertility in women [4]. In lowincome countries, impairments associated with STIs are a major cause of mother and child mortality and morbidity in adolescence and also during pregnancy $[18,19]$.

Factors affecting the spread of STIs, including HIV, have been documented in many epidemiological studies across different populations [20-24]. STIs and HIV share the same behavioral, socioeconomic and demographic risk factors [20, 25], including age at first sexual intercourse, inconsistent condom use, having multiple sexual partners, female sex, being single and the partner's sexual behaviour, location and culture. Furthermore, HIV infection increases the of other STIs [20, 24-28].

There is limited information on the prevalence and risk factors associated with STIs at population level in Swaziland, the country which has the highest prevalence of HIV infection worldwide. The availability of epidemiological data on STIs and associated risk factors in this population is essential for the development of successful prevention, diagnosis and management strategies in the country [29]. This study was therefore, conducted to determine the prevalence and risk factors associated with STIs among women of reproductive age in Swaziland.

\section{Methods \\ Study setting and population}

The study participants were women aged 15-49 years attending five healthcare facilities for routine healthcare and related services such as family planning, vaccination etc., from June to July 2015. This cross-sectional study included all women of reproductive age with a history of or who are currently sexually active and who provided written informed consent. The health care facilities (Mbabane Government hospital, Realign Fitkin Memorial (RFM) hospital, Hlatsikhulu hospital, Sithobela hospital and Siteki Public Health Unit) were located within the four political regions of Swaziland as shown in Table 1. The selection of the sites was based on the criteria of having fully functioning cervical cancer screening services, such as visual inspection with acetic acid (VIA) and cryotherapy. The purpose of including all fully functioning cervical cancer screening units was to achieve the goal of the 'see and treat" approach. All health facilities were using the "see and treat" approach as at the time of the study. VIA was performed, and all those who were VIA-positive were treated with cryotherapy and followed for 12 months. However, these results are not reported in this article.

\section{Sample size}

The sample size determination was based on the main research project aim, namely of establishing the burden of HPV infection and HPV-related conditions among women of reproductive age in Swaziland, where the value of the parameter(s) were not known in Swaziland. The prevalence of STIs investigated in the study was a secondary objective. Hence, the use of 50\%, which assumes maximum variability and the largest possible sample size, given the predefined precision of $\pm 5 \%$ and $95 \%$ confidence (5\% type I error). Based on this a, sample size of 384 subjects was required to be used. The sample was further increased by a margin of $10 \%$ to

\begin{tabular}{llll}
$\begin{array}{l}\text { Table } 1 \\
\text { site }\end{array}$ & Study sites per region and number of participants per \\
\hline Regions & Study site Code & Sites & $\begin{array}{l}\text { Participants } \\
\text { per-site }\end{array}$ \\
\hline Hhohho & H01 & $\begin{array}{l}\text { Mbabane government } \\
\text { hospital }\end{array}$ & 182 \\
Manzini & H02 & RFM hospital & 196 \\
Lubombo & H03 & Siteki Public Health Unit & 69 \\
& (PHU) & 69 \\
Shiselweni & H05 & Sithobela Hospital & 139 \\
Total & & Hlathikhulu Hospital & 655 \\
\hline
\end{tabular}


account for potential non-response and multiplied by a design effect (D) of 1.5. The final calculated sample size of the study was 650 women. However, a total of 655 women participated to the study.

\section{Sampling strategy}

The recruitment of participants was done in two sampling stages. Firstly, women were stratified by age (seven age-groups) and then sampled in each site using systematic random sampling (every third woman of each age), using the lottery method. The participants were selected from each site until the calculated sample size was achieved per site.

\section{Data collection}

Prior to questionnaire administration, willing participants were given all the necessary information about the study, their potential contribution, and their risks and benefits before they signed the informed consent form. Furthermore, all necessary information was included in the study information sheet and informed consent documents. A structured standardized questionnaire was administered by trained nurses to obtain detailed data on socio-demographic characteristics, and sexual, reproductive and gynaecologic histories. Thereafter, the nurse midwife inspected the perineal, vulvar, vaginal and cervical regions of each woman for evidence of genital warts, ulcers, discharge, inflammation or tenderness, and recorded all abnormalities according to the study protocol. Lastly, the specimen collection for each of the tests was performed (see details below). All participants found to be exhibiting genital warts were treated with the WHO-recommended $0.5 \%$ podophyllin tincture. Additionally, all participants presenting with STIs on syndromic diagnosis or/and who tested positive for STIs, were treatment as per WHO STIs management guidelines [4], which have been adopted by the Ministry of Health. Thereafter, the participants were invited to return in 1 week for review purposes as recommended by the guidelines. Participants were also requested to communicate with their sexual partners their need to visit the clinic or seek treatment, using the provided tracing slip with a suspected STI code of treatment.

Data were entered using EpiData 3.02 for Windows (The Epi Data Association Odense, Denmark). Each participant was assigned a unique study identity number that was used to link the questionnaire and the biological specimens. Personal information was blinded from the researcher and was kept on site for feedback of the results to the women, and validation of data.

\section{Biological specimen collection and testing}

After visual inspection of the vulva, a non-lubricated sterile disposable speculum was inserted and cervical cells were collected using the Xpert CT/NG/TV Endocervical swab (CT/NG/TV SWAB-50) (Cepheid, Sunnyvale, CA, 2014). After HIV pre-counselling, two $4 \mathrm{~mL}$ samples of blood (for HIV and syphilis testing) were collected in a vacutainer tube from participants consenting to HIV testing. All specimens were collected and transported daily to the National Referral Laboratory (NRL).

\section{Specimen testing}

All specimens testing were tested at the NRL, Mbabane, Swaziland. Since this work is part of the HPV/Cervical cancer study, only overall weighted HPV and HIV prevalence results are presented in this paper, for a purpose of assessing the association between the curable STIs and HPV and HIV.

\section{$\mathrm{CT} / \mathrm{NG}$ and TV testing}

Cepheid Xpert CT/NG assay was used to detect Chlamydia trachomatis (CT) and Neisseria gonorrhea (NG) infection, and the Cepheid Xpert TV Assay was used to detect Trichomonas vaginalis (TV) (Cepheid, Sunnyvale, CA, 2014) [30, 31]. All tests were performed according to the manufacturers' instructions. These are real-time polymerase chain reaction (PCR)-based assays for the simultaneous detection of CT/NG and TV from endocervical specimens.

\section{Treponema pallidum (syphilis)}

Treponema pallidum (Syphilis) testing was routinely conducted on all participants who consented to HIV testing using a commercially available standard Rapid Plasma Reagin (RPR) test (Atlas Medical, Cambridge, UK) [32], following the manufacturer's instructions. All reactive specimens were confirmed by Treponema pallidum Hemagglutination Assay (TPHA) (Omega Diagnostic, Scotland, UK) [33].

\section{HPV testing}

The HPV-DNA testing was done using the GeneXpert HPV assay (Xpert HPV Assay) (Cepheid, Sunnyvale, CA, 2014) [34] according to the manufacture's protocol. The Xpert HPV test gives results from six separate channels: (i) sample adequacy control (SAC), (ii) P1-HPV16, (iii) P2-HPV18/45, (iv) P3-HPV 31/33/35/52/58, (v) P4HPV51/59 and (vi) P5-HPV39/68/56/66. An individual specimen can be positive for more than one probe.

\section{HIV testing}

The Alere Determine HIV-1/2 Ag/Ab Combo test was used to detect both HIV-1/2 antibodies and free HIV-1 p24 antigen [35]. Reactive specimens were confirmed by Trinity Biotech Uni-Gold Recombigen HIV Test [36]. All participants who tested HIV positive were post- 
counselled and referred to health units offering the necessary HIV treatment, care and support services.

\section{Data and statistical analysis}

Data were processed and analysed using Stata 13.0SE (Stata corp. College station, Texas, USA). Data were checked for possible errors and missing values prior to analysis. Age and region-weighted analyses were done to estimate the overall STIs' prevalence and coinfection with HIV and hr-HPV.

Survey weighted analysis was done to adjust the sample characteristic to match the target population (15-49) that they were selected to represent. It is applied to bring the proportion of women in the sample in alignment with the portion of women in the target population. Therefore, all results are reported as weighted. Survey weighted prevalence and 95\% confidence intervals (CI) were calculated. In addition, assuming that our study subjects were representative of the female population of the same age strata, we used survey weights to extrapolate sample proportions to population totals (age-region weighted) to estimate burden counts, based on the 2007-2030 population projections aligned to the estimated 2014 population of 377169 women aged 1549 years [37]. Differences in prevalence by categorical variables such as site, age, HIV and hr-HPV were assessed using the survey weighted chi-square $\left(\chi^{2}\right)$ test. Odds ratios (unadjusted and adjusted) and 95\% CIs for potential risk factors associated with STIs were estimated using survey weighted logistic regression models. Variables that were significant at a cut-off of 0.2 in the bivariate regression analyses were selected for inclusion into the final multivariable model. An adjusted $p$-value of $<0.05$ was deemed statistically significant.

\section{Results}

\section{Characteristics of the study population}

A total of 655 women were enrolled in the study within the period of June - July 2015. All the participants had sufficient specimens for the four non-viral STIs testing and only 11 had sufficient specimen for hr-HPV. Table 2 summarizes the key characteristics of the study population. The mean ages ( \pm standard deviation [SD]) for enrolled women was $32.2( \pm 8.7)$ years. Their mean age at menarche was $14.4( \pm 1.7)$ years, at first intercourse was $17.9( \pm 2.9)$ years, and at first pregnancy was 19.4 $( \pm 3.9)$ years. Of the 655 participants, $571(88.7 \%)$ had been pregnant previously, $542(84.2 \%)$ had a history of contraceptive use, $272(42.6 \%)$ had a history of STIs, 116 (18.0\%) had STIs that had been treated in the past 12 months, 345 (53.6\%) were married or cohabiting, 227 (35.3\%) had not completed secondary/high school education, $340(53.0 \%)$ were unemployed and 513 (79.7\%) reported one lifetime sexual partner.

\section{Prevalence of STIs}

Table 3 shows the weighted prevalence of selected STIs in the samples of women aged 15-49 years. The overall STIs' weighted prevalence (excluding HIV and HPV) was 19.4\%, (95\% CI: 14.9-24.8) and individual prevalence for Trichomonas vaginalis (TV), Neisseria gonorrhoeae (NG), Chlamydia trachomatis (CT), Treponema pallidum (syphilis) and genital warts (GW) was 8.46.0, $7.0,1.4$ and $2.0 \%$, respectively. The overall weighted $\mathrm{hr}-$ HPV prevalence and HIV prevalence was $46.2 \%$ (95\% CI: 42.8-49.5), and 42.7\% (95\% CI: 35.7-46.2) respectively, (Table 3) (detailed data shown in a previously published article [38]). About 4.0\% (95\% CI: 2.3-6.0) had two or more STIs (multiple infections) and 6.0\% (95\% CI: 4.38.5) had triple infection (at least one STI, HIV and hrHPV infection) (Table 3). Among women with hr-HPV, 18.9\% (95\% CI: 13.1-26.3) had a single STI and 6.3\% (95\% CI: 3.3-11.7) had multiple STIs. Among HIV positive women, $17.7 \%(95 \%$ CI: $11.5-26.9)$ had one STI, while $4.2 \%$ (95\% CI: $1.5-11.3)$ had multiple STIs (Table 4). About 6.3\% (95\% CI: 4.4-8.9) women had STIs, HPV and HIV combined coinfections.

\section{Population burden estimates}

Tables 3 and 4 show the population burden estimates. Population burden estimates to extrapolate absolute burden counts of the different STIs were made based on the 2007-2030 population projections aligned to the 2014 population estimates of women aged 15-49 years. The overall population burden was estimated at 72990 (95\% CI: 51 111-94 871) as depicted on Table 3. When stratified by each STI, 30132 (95\% CI: 16 633-43 631) were estimated to have TV, 22055 (95\% CI: 11 986-32 124) have NG, 25024 (95\% CI: 11 251-38 797) have CT, 5072 (95\% CI: 1 822-8 322) have Treponema pallidum (syphilis), and 6111 (95\% CI: 470-12692) have GW. Multiple STIs estimates were 13995 (95\% CI: 7 092-20 898) and triple STIs were 23310 (95\% CI: 14 193-32 427). Among HIV positive women, the population burden counts for single STIs were 32158 (95\% CI: 20 200-44 115) and for multiple infection 10798 (95\% CI: 4 032-17 564). Among hr-HPV positive women the population burden counts for single and multiple infection were 27163 (95\% CI: 14 941-39 386) and 6367 (95\% CI: 159-12 893), respectively) (Table 4).

\section{Prevalence of STIs by selected socio-demographic characteristics of the women}

Table 5 shows the prevalence of STIs by selected sociodemographic characteristics of the women, and the risk factors associated with STIs (univariable and multivariable logistic regressions). The prevalence of STIs decreased with increasing age, with the highest burden among the 15-19 and 24-29 age groups (29.2 and 27.0\% 
Table 2 Socio-demographic characteristics of the study population $(N=655)$

\begin{tabular}{|c|c|}
\hline Demographics & n (\%) \\
\hline \multicolumn{2}{|l|}{ Age: $n(\%)$} \\
\hline Mean \pm SD (range) & $32.2 \pm 8.7$ \\
\hline $15-19$ & $39(6.1)$ \\
\hline $20-24$ & $111(17.2)$ \\
\hline $25-29$ & $131(20.3)$ \\
\hline $30-34$ & $116(18.0)$ \\
\hline $35-39$ & $103(16.0)$ \\
\hline $40-44$ & $80(12.4)$ \\
\hline $45-49$ & $75(11.6)$ \\
\hline \multicolumn{2}{|l|}{ Marital status: n (\%) } \\
\hline Single & $266(41.3)$ \\
\hline Cohabiting & $38(5.9)$ \\
\hline Married & $307(47.7)$ \\
\hline Divorced/separated & $22(3.4)$ \\
\hline Widow & $11(1.7)$ \\
\hline \multicolumn{2}{|l|}{ Education: n (\%) } \\
\hline Never been to school & $24(3.7)$ \\
\hline Primary & $130(20.2)$ \\
\hline Secondary/High & $373(57.9)$ \\
\hline Tertiary & $117(18.2)$ \\
\hline \multicolumn{2}{|l|}{ Occupation: n (\%) } \\
\hline Unemployed & $340(53.0)$ \\
\hline Employed & $255(39.8)$ \\
\hline Self-employed & $46(7.2)$ \\
\hline \multicolumn{2}{|l|}{ Ever pregnant : n (\%) } \\
\hline Yes & $571(88.7)$ \\
\hline No & $64(9.9)$ \\
\hline Missing & $9(1.4)$ \\
\hline Age at first pregnancy: Mean age (SD) & $19.4(3.9)$ \\
\hline \multicolumn{2}{|l|}{ No. pregnancies: n (\%) } \\
\hline 0 & $6(1.0)$ \\
\hline 1 & $139(24.3)$ \\
\hline 2 & $127(22.2)$ \\
\hline $3+$ & 297(46.1) \\
\hline Age Menarche: Mean (SD) & $14.39(1.7)$ \\
\hline Age at first intercourse: Mean age (SD) & $17.90(2.9)$ \\
\hline \multicolumn{2}{|l|}{ Number of Sexual life partner: $\mathrm{n}(\%)$} \\
\hline 0 & $33(5.1)$ \\
\hline 1 & $513(79.7)$ \\
\hline 2 & $61(9.5)$ \\
\hline $3+$ & $43(6.7)$ \\
\hline
\end{tabular}

Currently using contraceptives: $\mathrm{n}(\%)$
Table 2 Socio-demographic characteristics of the study population ( $N=655)$ (Continued)

\begin{tabular}{ll}
\hline No & $95(14.8)$ \\
Missing & $7(1.1)$ \\
Ever had STI: $\mathrm{n}(\%)$ & \\
Yes & $272(42.6)$ \\
No & $337(52.7)$ \\
Don't remember & $30(4.7)$ \\
STIs treated in the past 12 months: $\mathrm{n}(\%)$ & \\
Yes & $116(18.0)$ \\
No & $520(80.9)$ \\
Don't know & $7(1.1)$ \\
\hline
\end{tabular}

respectively) (Table 5). There was no statistically significant difference between age-group observed for all or individual STIs, although the prevalence of CT was slightly higher among women aged $15-19$ years $(12.1 \%$, 95\% CI: 3.4-35.5, $p=0.32)$, NG was higher among $20-24$ years old $(12.1 \%$, 95\% CI: 5.4-25.1, $p=0.41)$ while TV was higher among 25-29 years old $(13.9 \%, 95 \%$ CI: $10.6-18.1, p=0.15)$ as compared to all ages (data not shown).

The prevalence of STIs was significantly higher among single women $(26.4 \%)$ as compared to married women $(11.2 \%)(p=0.001)$. Women with secondary/high school education had a prevalence of $22.2 \%$ as compared to women who had never been to school (9.1\%). Unemployed and self-employed women had a prevalence of 21.6 , and $21.8 \%$ respectively as compared to employed women (14.7\%). There was no statistically significant difference between women who reported being pregnant before as compared to women who had never been pregnant $(25.2 \%$ vs $18.3 \%, p=0.323)$.

Based on the univariate analysis: the mean age, being married, increasing number of pregnancies and not using condoms with ones' regular partner were inversely associated with STIs' risk. Significant differences in proportions regarding those married $(p<0.001)$, the number of sexual partners $(p<0.001)$ and contraceptive use by age group $(p<0.001)$ was observed. Having two and three sexual life-time partners was associated with an increased risk $\mathrm{OR}=5.1(95 \% \mathrm{CI}: 1.2-21.5)$ and $\mathrm{OR}=8.4$, (95\% CI: 1.3-54.2) respectively for STIs. Being hr-HPV positive was significantly associated with increased risk of STIs $(\mathrm{OR}=2.1,95 \% \mathrm{CI}: 1.3-3.6)$. In the final logistic regression model (multivariate analysis), factors independently associated with increased risk of STIs were: being employed $(\mathrm{OR}=2.2, \quad 95 \%$ CI: 1.0-4.7), selfemployed ( $\mathrm{OR}=2.8,95 \% \mathrm{CI}: 1.5-5.5)$ and $\mathrm{hr}-\mathrm{HPV}$ positive status $(\mathrm{OR}=2.0,95 \% \mathrm{CI}$ : $1.3-3.1)$. Being married, mean age and not using a condom one's with regular partner were found to be inversely associated in the final model $(\mathrm{OR}=0.4,95 \% \mathrm{CI}: 0.3-0.7, \mathrm{OR}=0.92,95 \% \mathrm{CI}$ : 
Table 3 The prevalence of sexually transmitted infections (STIS) among women aged 15-49 in Swaziland $(n=655)$

\begin{tabular}{llllll}
\hline STls & Positive $(n)$ & Crude Prevalence (\%) & Survey weighted prevalence \% (95\% Cl) & Population burden $^{\text {a }}$ & $95 \%$ Cl \\
\hline Overall & 114 & 17.4 & $19.4(14.9-24.8)$ & 72990 & $51111-94871$ \\
TV & 51 & 4.7 & $8.4(5.4-12.8)$ & 30132 & $16633-43631$ \\
NG & 35 & 5.2 & $6.0(3.8-9.4)$ & 22055 & $11986-32124$ \\
CT & 38 & 5.8 & $7.0(4.1-11.2)$ & 25024 & $11251-38797$ \\
Treponema pallidum (syphilis) & 9 & 1.2 & $1.4(1.1-10.2)$ & 5072 & $1822-8322$ \\
Genital warts & 6 & 1.0 & $2.0(1.0-11.4)$ & 6111 & $470-12692$ \\
HIV & 276 & 42.1 & $42.7(35.7-46.2)$ & 153276 & $127336-179216$ \\
Hr-HPV $(n=644)$ & 273 & 42.1 & $46.2(42.8-49.5)$ & 174046 & $153294-194797$ \\
Multiple STIs ${ }^{b}$ & 20 & 3.1 & $4.0(2.3-6.0)$ & 13995 & $7092-20898$ \\
${ }_{\text {CTriple STIs }(n=644)^{d}}$ & 38 & 5.9 & $6.3(4.4-8.9)$ & 23310 & $14193-32427$
\end{tabular}

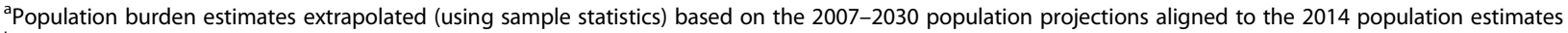

${ }^{\mathrm{b}}$ Multiple STIs - having two or more of the screened 5 STIs

'Triple infection: at least one other STI including HIV and hr-HPV infection

${ }^{\mathrm{d}} \mathrm{A}$ total of 11 women had insufficient specimen for hr-HPV testing therefore for the analysis for Triple STIs done on $N=644$

0.89-0.95, and $\mathrm{OR}=0.5,95 \% \mathrm{CI}: 0.3-0.9)$ respectively, as compared to not having a sexual life partner.

Individual STI association with HIV and hr-HPV was assessed. There was a significant inverse association between HIV and CT $(p=0.001)$ but there was a significant positive association between HIV and syphilis $(p=0.001)$. There was a significant positive association between hrHPV and NG and CT ( $p=0.020$ and $p=0.001)$. A significant association with TV and hr-HPV $(p=0.058)$ was observed (results not shown).

\section{Discussion}

The current study in Swaziland shows a high prevalence of STIs (19.4\%), corresponding to 72990 women of reproductive age with STIs. Our data suggests that TV was the most prevalent curable STI (8.4\%) among those examined in this study. Furthermore, the prevalence of HIV remains significantly high $(42.7 \%)$ in this population. The prevalence of the STIs decreased with increasing age however, differences by age groups were not statistically significant. A high percentage of women infected with hr-HPV had one STI (18.8\%), while $6.3 \%$ had multiple STIs. Single women were at higher risk of being infected with STIs compared to married women $(26.4 \%$ vs $11.2 \%, p=0.001)$. A proportion of the women had triple co-infection (6.3\%), interact either directly with one another or indirectly via the host's resources or immune system. Studies have demonstrated that, as compared to infections of single pathogen species, these interactions within coinfected hosts can alter the transmission, clinical progression and control of multiple infectious diseases $[39,40]$. In the final logistic regression model, being employed, self-employed and hr-HPV infection status were risk factors positively associated with STIs.
In this study, we collected primary data and biological specimens using a standardized methodology. This is the first study evaluating the prevalence of STIs among women of reproductive age not attending antenatal care in Swaziland. We were able to extrapolate our results on the prevalence of STIs as well as genital warts to the female population in the same age groups of 1549 years-old using the 2007-2030 population projections aligned to the 2014 population estimates [37]. Another strength of our study is that STIs such as NG, TV and CT were detected using the Gene Xpert PCR (Xpert CT/NG and Xpert TV) which, is a highly sensitive laboratory method for detecting genital infection. An important limitation of the study is the lack of generalizability of the results to the general Swazi female population beyond the age groups studied (15-49 years). In addition, since the study subjects were recruited from heath care facilities, it is arguable that they may not be truly representative of the general population. This could have introduced a selection bias. However, weighting was applied when reporting the summary results for the whole study sample. Lastly, the study participants were required to recall past events, which could result in compromising the accuracy of information provided, due to recall bias. Finally, due to limited resources for our study we did not genotype or test for LR-HPVs.

The high prevalence of STIs (19.4\%) in this population indicates that STIs are a serious public health problem in Swaziland. Our findings were consistent with previous studies from similar populations across the Southern African Development Community region (SADC) and other sub-Saharan regions [13, 15, 41-43]. The prevalence of each of the STIs detected among the study population was less than $10 \%$ (7.0\% for CT, $6.0 \%$ for NG, $8.4 \%$ for TV and $1.4 \%$ for syphilis), but this is still high, which compared to global estimates, where the 


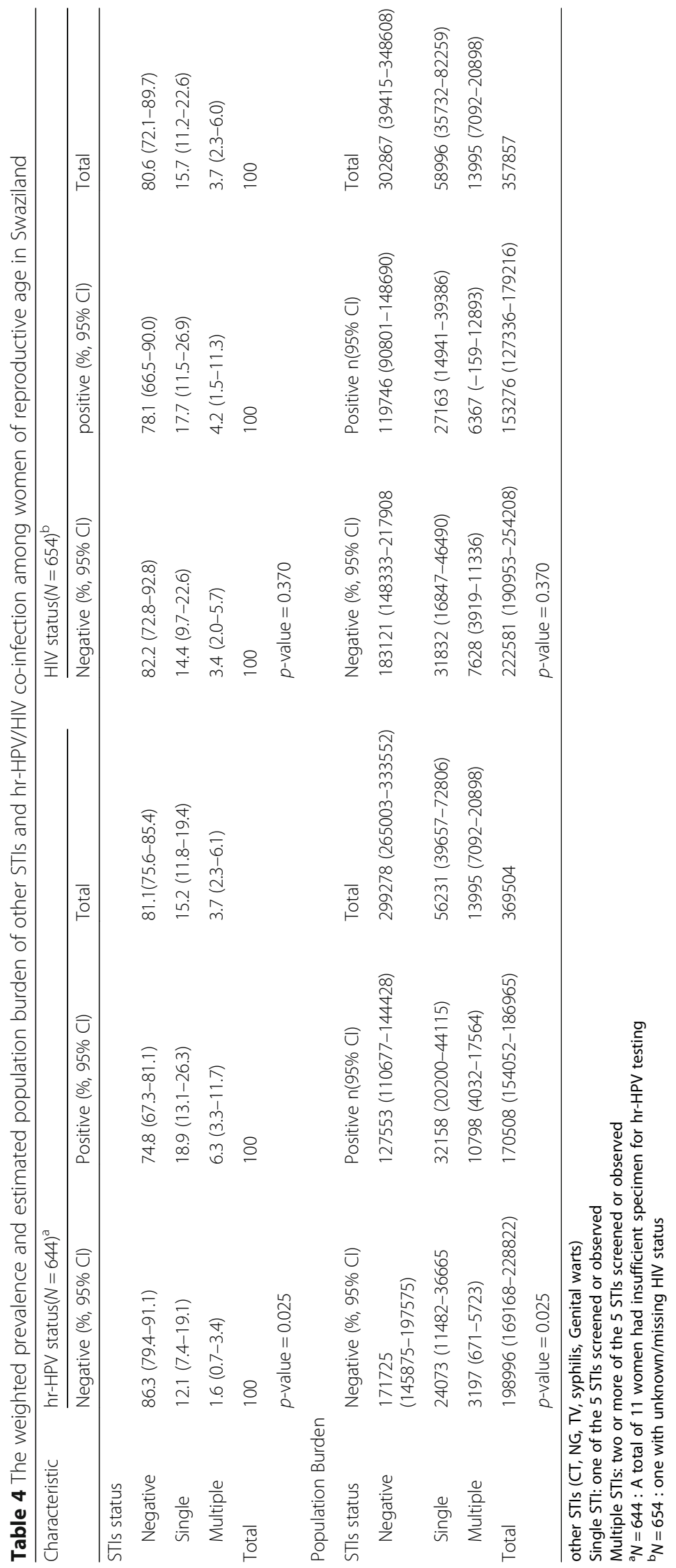


Table 5 Risk factors associated with STls among women aged 15-49 years in Swaziland $(N=655)$

\begin{tabular}{|c|c|c|c|c|c|c|}
\hline \multirow[t]{2}{*}{ Risk factors } & \multicolumn{2}{|c|}{ STIs (Weighted Prevalence) } & \multicolumn{2}{|c|}{ Unadjusted (Univariate) } & \multicolumn{2}{|c|}{ Adjusted (Multivariable) } \\
\hline & Number + ve/Total & $(\%, 95 \% \mathrm{Cl})$ & OR $(95 \% \mathrm{Cl})$ & $P$-value & $\mathrm{OR}^{\mathrm{a}}(95 \% \mathrm{Cl})$ & $P$-value \\
\hline Overall & $114 / 655$ & $19.3(14.9-24.8)$ & & & & \\
\hline \multicolumn{7}{|l|}{ Age } \\
\hline Mean \pm SD (range) & $114 / 655$ & $27.1(25.9-28.2)$ & $0.9(0.8-0.9)$ & 0.001 & $0.9(0.8-0.9)$ & $<0.001$ \\
\hline $15-19$ & $13 / 45$ & $29.2(14.3-59.4)$ & 1 (ref) & & & \\
\hline $20-24$ & $26 / 110$ & $22.7(13.1-37.4)$ & $0.7(0.2-2.1)$ & 0.520 & $\ldots$ & $\ldots$ \\
\hline $24-29$ & $34 / 127$ & $27.0(19.0-38.1)$ & $0.9(0.4-2.1)$ & 0.797 & $\ldots$. & $\ldots$ \\
\hline $30-34$ & 20/143 & $13.0(6.0-3161)$ & $0.4(0.1-1.1)$ & 0.081 & & $\ldots$ \\
\hline $35-39$ & $14 / 94$ & $14.5(7.7-28.8)$ & $0.4(0.1-1.2)$ & 0.110 & $\ldots$ & $\ldots$ \\
\hline $40-44$ & $6 / 78$ & $6.9(1.5-29.9)$ & $0.2(0.03-1.1)$ & 0.067 & $\ldots$ & $\ldots$ \\
\hline $45-49$ & $1 / 58$ & $1.0(0.1-8.7)$ & $0.03(0-0.3)$ & 0.004 & $\ldots$ & $\ldots$ \\
\hline \multicolumn{7}{|l|}{ Marital status } \\
\hline Single & $66 / 271$ & $26.4(18.5-37.4)$ & 1 (ref) & & & \\
\hline Living with partner/Cohabiting & $9 / 38$ & $24.2(9.8-62.3)$ & $0.89(0.3-2.5)$ & 0.819 & & \\
\hline Married & $36 / 313$ & $11.2(6.7-18.9)$ & $0.35(0.2-0.6)$ & 0.001 & $0.4(0.3-0.7)$ & 0.001 \\
\hline Divorced/separated & $3 / 22$ & $15.1(4.9-38.3)$ & $0.5(0.13-1.9)$ & 0.289 & $\ldots$ & $\ldots$ \\
\hline widow & $0 / 11$ & 0 & - & - & $\ldots$ & $\ldots$ \\
\hline \multicolumn{7}{|l|}{ Education: } \\
\hline Never been to school & $2 / 24$ & $9.4(19.0-36.0$ & 1 (ref) & & & \\
\hline Primary & $23 / 133$ & $21.4(10.5-47.8)$ & $2.6(0.4-16.9)$ & 0.299 & $\ldots$ & $\ldots$ \\
\hline Secondary/High & $78 / 380$ & $22.2(15.4-31.3)$ & $2.7(0.5-15.4)$ & 0.243 & $\ldots$ & $\ldots$ \\
\hline Tertiary & $11 / 118$ & $7.3(3.5-16.9)$ & $0.8(0.1-5.4)$ & 0.777 & $\ldots$ & $\ldots$ \\
\hline \multicolumn{7}{|l|}{ Occupation: } \\
\hline Unemployed & $67 / 346$ & $21.6(14.2-32.9)$ & 1 (ref) & & 1 (ref) & \\
\hline Employed & $39 / 258$ & $14.7(9.8-22.0)$ & $0.63(0.34-1.16)$ & 0.129 & $2.2(1.0-4.7)$ & 0.045 \\
\hline Self-employed & $8 / 48$ & $21.8(8.0-47.4)$ & $1.01(0.32-3.19)$ & 0.982 & $2.8(1.5-5.5)$ & 0.002 \\
\hline \multicolumn{7}{|l|}{ Pregnant before } \\
\hline Yes & $99 / 582$ & $18.3(13.5-24.4)$ & 1 (ref) & & & \\
\hline No & $13 / 64$ & $25.2(12.6-48.9)$ & $1.51(0.65-3.46)$ & 0.323 & $\ldots$ & $\ldots$ \\
\hline No. of pregnancies (Mean) & $114 / 655$ & $2.2(1.9-2.5)$ & $0.8(0.7-0.9)$ & 0.008 & $\ldots$ & $\ldots$ \\
\hline Age Menarche (Mean age) & $114 / 655$ & $13.97(13.5-14.4)$ & $0.9(0.7-1.1)$ & 0.166 & $\cdots$ &. \\
\hline Age at first sex (mean age) & $114 / 655$ & $17.2(16.5-17.9)$ & $0.96(0.9-1.1)$ & 0.370 & $\ldots$. & $\ldots$. \\
\hline Number of sexual partners & & $2.0(0.6-3.4)$ & $1.3(1.4-1.5)$ & $<0.001$ & $1.2(0.9-1.5)$ & 0.197 \\
\hline 0 & $3 / 33$ & $6.2(14.2-23.6)$ & 1 (ref) & & $\ldots$ & $\ldots$ \\
\hline 1 & $84 / 522$ & $18.4(14.2-23.6)$ & $3.4(1.0-12.3)$ & 0.056 & & $\ldots$ \\
\hline 2 & $16 / 62$ & $25.1(11.3-46.8)$ & $5.1(1.1-21.5)$ & 0.028 & $\ldots$ & $\ldots$ \\
\hline $3+$ & $11 / 37$ & $35.6(15.7-53.3)$ & $8.4(1.3-54.2)$ & 0.027 & $\ldots$ & $\ldots$ \\
\hline \multicolumn{7}{|l|}{ Condom use with regular partner } \\
\hline Yes & $93 / 457$ & $21.6(14.8-31.2)$ & 1 (ref) & & 1 (ref) & \\
\hline No & 20/194 & $13.1(5.7-29.1)$ & $0.5(0.28-0.9)$ & 0.022 & $0.5(0.3-0.9)$ & 0.034 \\
\hline \multicolumn{7}{|l|}{ Ever had STI } \\
\hline Yes & $41 / 278$ & $16.2(10.9-23.4)$ & 1 (ref) & & & \\
\hline No & $63 / 342$ & $19.8(15.2-25.3)$ & $1.28(0.8-2.0)$ & 0.246 & $\ldots$ & $\ldots$ \\
\hline Don't remember & $7 / 30$ & $31.8(12.0-61.3)$ & $2.42(0.7-7.8)$ & 0.136 & $\ldots$ & $\ldots$ \\
\hline
\end{tabular}


Table 5 Risk factors associated with STIs among women aged 15-49 years in Swaziland ( $N=655)$ (Continued)

\begin{tabular}{|c|c|c|c|c|c|c|}
\hline \multicolumn{7}{|c|}{ STIs treated in the past 12 months } \\
\hline Yes & $24 / 118$ & $22.6(13.5-35.5)$ & 1 (ref) & & & \\
\hline No & $89 / 529$ & $18.7(14.7-23.6$ & $0.8(0.5-1.4)$ & 0.376 & $\ldots$ & $\cdots \cdots$ \\
\hline Don't know & $1 / 7$ & $13.9(12.6-67.3)$ & $0.6(0.4-8.1)$ & 0.654 & $\ldots$ & $\ldots$ \\
\hline \multicolumn{7}{|l|}{ HIV Status: } \\
\hline Negative & $55 / 373$ & $17.7(13.4-23.0)$ & 1 (ref) & & & \\
\hline Positive & $59 / 281$ & $21.9(15.2-30.4)$ & $1.3(0.9-2.0)$ & 0.204 & $\ldots$ & $\ldots$ \\
\hline \multicolumn{7}{|l|}{ hr-HPV status: } \\
\hline Negative & $46 / 371$ & $13.7(8.9-20.6)$ & 1 (ref) & & 1 (ref) & \\
\hline Positive & $64 / 273$ & $25.2(19.0-32.7)$ & $2.1(1.3-3.6)$ & 0.007 & $2.0(1.3-3.1)$ & 0.002 \\
\hline
\end{tabular}

prevalence for $\mathrm{CT}$ among women range from 2.4 to $6.9 \%$, NG from $0.3 \%$ to 1.2 , TV from 1.9 to $7.8 \%$ and syphilis from 0.2 to 1.3 [44]. Results from the firstand second STI sentinel surveillance surveys conducted in 2003 and 2005 respectively in Swaziland, showed that the prevalence of STIs, such as CT, NG, TV and syphilis, and other reproductive tract infections, such as bacterial vaginosis and candidiasis, continue to be among the highest in the country $[45,46]$. However, a decline in syphilis has been noted in recent years. According to the 11th Sentinel Surveillance report 2008, recent syphilis infection was tested using Treponema pallidum haemagglutination (TPHA), and the prevalence was $1.9 \%$ while $4.7 \%$ showed a history of syphilis infection by RPR results [47]. A comparison between the 2008 report and recent syphilis infection shows a decreasing trend (1.9\%) compared to current study findings (1.4\%). The high prevalence of the curable STIs in this population might be linked to the limitation of syndromic STI management, which does not give specific aetiological diagnosis; therefore, most infections are missed by this approach [48, 49]. Although syndromic management has proven to be cost-effective in resource limited settings, our findings demonstrate the evidence for the need of a strong national STIs' surveillance system.

HIV remains one of the major public health challenges in Swaziland, with the highest prevalence among women of reproductive age $[50,51]$. This high prevalence reported in our study was consistent with other studies. However, our results were slightly higher as compared to Bicego et al's study on recent patterns in populationbased HIV among women age 18-49 years (42.7\% vs. $39 \%$ ) [50]. In a country that has the highest HIV prevalence in the world, the challenge remains to assist uninfected individuals in gaining access to high quality prevention services, including early detection and treatment of curable STIs.
The observed high prevalence of STIs in the younger age groups as compared to the older age groups in our study is consistent with other studies [41, 52, 53]. The decreasing STIs prevalence with increasing age observed in our study, might be the results of the high susceptibility of younger women, lack of protective immune response development, and more risky behavior, such as an earlier age at first intercourse, a high number of sexual partners, and unprotected sex [52].

In this current study, single women and women living with partners (but not married) had the highest prevalence of STIs. Similar evidence has been found in other studies [54, 55]. In our multivariate analysis, married women were $60 \%$ less likely to be at risk of STIs as compared to single women $(\mathrm{OR}=0.4)$. A similar outcome was found in others studies showing being married is a protective factor $[48,56]$.

As far as education is concerned, our findings have shown that women with a lower level of education are most likely to have an STI. Studies have shown that women with less education have an increased risk of STIs [13, 57, 58]. Kakaire et al. highlighted that women with lower education tend to lack formal employment and may be completely dependent on the male sexual partner and unable to negotiate safer sex. They are less likely to access STI preventative information and healthcare services [13]. According to Muula, unemployment may leave women with limited alternatives where they may resort to engaging in high risk behavior such as becoming sex workers or to engaging in transactional sex in which they provide sex in exchange for money and material resources from a partner [59]. However, our study found that employed and self-employed women were at high risk of STIs (OR: 2.2 and OR: 2.8 respectively) as compared to unemployed women. The types of employment might explain the high risk of STIs among employed and self-employed women in our study and the in which businesses they are involved. There is 
evidence suggesting that women working in high-risk occupation such bars, food facilities, guesthouses and similar facilities are at high risk of STI infection [48].

In this study, the risk associated with STIs among women with two or more sexual life-time partners was five to eight times higher as compared to women with no sexual partners in the univariate analysis. Our findings were consistent with other studies which reported that sexual activity with many partners increases the odds of STIs [53, 54]. However, the association was not statistically significant in our study following adjustment for all possible confounding factors (age, marital status, level of education, occupation, history of pregnancy, age at first sex, history of STIs, STIs treated in the past 12 months, and HIV status), which negatively confounded this relationship. There was a very high collinearity between the number of sexual partners and some of the confounding factors, which may have further affected the coefficients in the stepwise multivariable regression. Though evidence from studies done in South Africa [41, 42], Zambia [60], and Tanzania [48] has demonstrated that having more than one or concurrent lifetime sexual partners was among the risk factors associated with STIs.

Inconsistent condom use as a risk factor for STIs in women has been demonstrated in other studies [61, 62]. In contrast to our study, not using condoms with regular partners was inversely associated with STIs. The possible plausible explanation of our findings might be that, women who reported not using condoms with regular partners had one faithful partner or they had been treated for STIs prior to data collection. However, this will require further investigation. Moreover, condoms remain a critical part in a comprehensive and practical approach to the prevention of STIs [63].

HIV positive status was not associated with STIs in both analyses but when assessed by individual STIs, a significant inverse association between HIV and CT, and significant positive association between HIV and syphilis were observed. No statistically significant association between HIV and NG or TV was observed in the current study. However, studies have indicated that depending on the STI involved and the population, NG, CT, TV, HPV and syphilis increase the risk of HIV acquisition and transmission from two to eight times or more $[4,6,7]$. Furthermore, biological findings support the mechanisms for STIs increasing HIV acquisition and transmission through direct mucosal disruption, recruitment of HIV target cells to the genital tract, and by increased HIV load in plasma and genital secretions [10]. High levels of untreated STIs in sub-Saharan countries are linked to high HIV transmission rates and have been postulated to have contributed to the high prevalence of HIV in the region [16].
A vital clinical and public health consequence of our findings is that hr-HPV was the most significant risk factor associated with STIs infection in both univariate and multivariate analysis (unadj-OR $=2.1$ and Adj-OR $=2.0$ ). When assessing the association between hr-HPV and individual STIs, there was a significant positive association between hr-HPV and NG and CT. The strong association between HPV infection and STIs has been demonstrated in previous studies, where infection with hr-HPV types, was a risk factor for CT and NG infection [64-66]. These findings are significantly of high importance for policy and prevention programmes to include HPV infection in the existing STIs prevention programmes in the country.

The curable STIs (CT, NG, TV, and syphilis), and HIV and HPV are sexually transmitted infections, which share the same transmission route and behavioural risk factors. If the curable STIs are not treated, they can lead to a variety of different health risks and greatly increase HIV/HPV transmission risk with further chronic health implications. Collectively, our data have shown the significantly high prevalence of and association between STIs and HIV/HPV coinfection, which tends to subscribe to the new concept in which HIV and HPV infections may be bi-directional, each increasing the risk of the other [67-69] STIs increase the risk of HIV/HPV co-infection. The high hr-HPV/HIV coinfection with the curable STIs and resultant high population burden has implications for both cervical cancer and also for the United Nations (UN) sustainable development goal 3, target 3.3 (SDG 3) [70] (goal 3 aims to reduce new HIV infection through ensuring health and well-being for all, at every stage of life). The STIs are positively increasing the risk of HIV/HPV acquisition, which will make it impossible for countries like Swaziland to achieve SDG 3 target 3.3. Therefore, STIs' control and HPV vaccination, combined with periodic HIV screening and referral to early treatment is needed to end the HIV epidemic in Swaziland.

\section{Conclusion}

In conclusion, although STIs may be treated and are curable, they remain a major public health challenge in Swaziland where HIV infection is highly prevalent. Our study indicates that there is a need for a comprehensive STI screening, surveillance and treatment programme in the country.

\section{Abbreviations}

CT: Chlamydia trachomatis; HIV: Human immunodeficiency virus; $\mathrm{Hr}-$ HPV: High-risk human papillomavirus; NG: Neisseria gonorrhoeae; NRL: National referral laboratory; RFM: Realign Fitkin Memorial Hospital; SDG: United Nations Sustainable Development Goal; STIs: Sexually transmitted infections; TPHA: Treponema pallidum Hemagglutination Assay; TV: Trichomonas vaginalis; VIA: Visual inspection with acetic acid 


\section{Acknowledgements}

We thank the Kingdom of Swaziland Ministry of Health for allowing us to implement the study, and the support from International Agency for Research on cancer (IARC), WHO- Swaziland local office, Ministry of Health Epidemiology Unit and Sexually Reproductive Health Unit (SRH) and University of Alabama at Birmingham (Minority Health International Research Training (MHIRT) grant). We are so thankful for the laboratory support and capacity building from Cepheid Europe and South Africa.

\section{Funding}

The study was funded by the University of KwaZulu-Natal College of Health Sciences Doctoral Research Scholarship grant and another part funding from Health and Welfare Sector Education and Training Authority (HWSETA). The funder had no role in the study design, data collection and analysis, decision to publish.

\section{Availability of data and materials}

Data from this study are the property of the Government of Swaziland and University of KwaZulu-Natal and cannot be made publicly available. All interested readers can access the data set from the Secretariat SEC Committee (Swaziland Scientific and Ethics Committee) and University of KwaZulu-Natal Biomedical Research Ethics Committee (BREC) from the following contacts: The Chairman Scientific and Ethics Committee Ministry of Health, Swaziland P.O. Box 5 Mbabane, H1 Tel: (+268) 2404231 Fax: (+268) 2404 2092. The Chairperson BIOMEDICAL RESEARCH ETHICS ADMINISTRATION Research Office, Westville Campus, Govan Mbeki Building University of KwaZulu-Natal P/Bag X54001, Durban, 4000 KwaZulu-Natal, South Africa Tel.: +27 312604769 Fax: +27 31260 4609 Email: BREC@ukzn.ac.za

\section{Authors' contributions}

TG designed the study, data collection, carried out the analyses, and wrote the paper. BS analysed data and supervised writing up of manuscript: DX, PEJ, EW, NB, CDS, JMT supervised the study, and analyses, wrote the paper, reviewed and modified with their contributions to the original manuscript. All authors have read and approved of the final version of the manuscript.

\section{Competing interests}

The authors declare that they have no competing interests.

\section{Consent for publication}

Not applicable.

\section{Ethics approval and consent to participate}

The study was approved by the Swaziland Scientific Ethics Committee (MH599C/FW00015267/IRB0009688) and the Biomedical Research Ethics Committee of the University of KwaZulu-Natal (BE 242/14). Ethics committees approved written informed consent, which was obtained from all the participants prior participating to the study. All sexually active women aged between 15 and 49 years attending various reproductive health clinics and other units from all the study sites, were eligible for the study. In Swaziland according to national guidelines for HIV testing and counselling, the consenting age is 12 years [71]. All women who tested positive for HIV and/or STI received treatment and counselling.

\section{Publisher's Note}

Springer Nature remains neutral with regard to jurisdictional claims in published maps and institutional affiliations.

\section{Author details}

'Discipline of Public Health, School of Nursing and Public Health, University of KwaZulu-Natal, 2nd Floor George Campbell Building, Mazisi Kunene Road, 4041 Durban, South Africa. ${ }^{2}$ Walter Sisulu University, Umtata, South Africa. ${ }^{3}$ Epidemiology Unit, Ministry of Health and Social Welfare, Mbabane, Swaziland. ${ }^{4}$ Department of Epidemiology, University of Alabama, Birmingham, USA. ${ }^{5}$ Department of Medical Epidemiology and Biostatistics, Karolinska Institutet, Stockholm, Sweden. ${ }^{6}$ Department of Research, Cancer Registry of Norway, Institute of Population-Based Cancer Research, Oslo, Norway. ${ }^{7}$ Department of Community Medicine, Faculty of Health Sciences, University of Troms $\varnothing$, The Arctic University of Norway, Troms $\varnothing$, Norway. ${ }^{8}$ Genetic Epidemiology Group, Folkhälsan Research Center, Helsinki, Finland. ${ }^{9}$ World Health Organization; Department of Reproductive Health and Research, Geneva, Switzerland.
Received: 15 February 2017 Accepted: 16 May 2017

Published online: 25 May 2017

\section{References}

1. Genuis SJ, Genuis SK. Managing the sexually transmitted disease pandemic: a time for reevaluation. Am J Obstet Gynecol. 2004;191(4):1103-12.

2. Menendez C, Castellsague X, Renom M, Sacarlal J, Quinto L, Lloveras B, Klaustermeier J, Kornegay JR, Sigauque B, Bosch FX et al.: Prevalence and risk factors of sexually transmitted infections and cervical neoplasia in women from a rural area of southern Mozambique. Infect Dis Obstet Gynecol. 2010;2010:9. doi: 10.1155/2010/609315. https://www.hindawi.com/journals/idog/2010/609315/.

3. World Health Organisation. Report on global sexually transmitted infection surveillance 2013. Geneva: WHO; 2014.

4. World Health Organisation. Sexually transmitted infections (STIs), fact sheet №110. Geneva: WHO; 2015.

5. World Health Organisation. Global prevalence and incidence of selected curable sexually transmitted infections. 2012.

6. Boily MC, Baggaley RF, Wang L, Masse B, White RG, Hayes RJ, Alary M. Heterosexual risk of HIV-1 infection per sexual act: systematic review and meta-analysis of observational studies. Lancet Infect Dis. 2009;9(2):118-29.

7. Jin F, Prestage GP, Imrie J, Kippax SC, Donovan B, Templeton DJ, Cunningham A, Mindel A, Cunningham PH, Kaldor JM, et al. Anal sexually transmitted infections and risk of HIV infection in homosexual men. J Acquir Immune Defic Syndr. 2010;53(1):144-9.

8. Grosskurth H, Gray R, Hayes R, Mabey D, Wawer M. Control of sexually transmitted diseases for HIV-1 prevention: understanding the implications of the Mwanza and Rakai trials. Lancet. 2000;355(9219):1981-7.

9. Kaul P, Gupta I, Sehgal R, Malla N. Trichomonas vaginalis: random amplified polymorphic DNA analysis of isolates from symptomatic and asymptomatic women in India. Parasitol Int. 2004;53(3):255-62.

10. Ward HRM. Contribution of sexually transmitted infections to the sexual transmission of HIV. Curr Opin HIV AIDS. 2010;4:305-10.

11. Chaturvedi AK, Madeleine MM, Biggar RJ, Engels EA. Risk of human papillomavirus-associated cancers among persons with AIDS. J Natl Cancer Inst. 2009:101(16):1120-30.

12. Johnson $L F$, Lewis DA. The effect of genital tract infections on HIV-1 shedding in the genital tract: a systematic review and meta-analysis. Sex Transm Dis. 2008;35(11):946-59.

13. Kakaire O, Byamugisha JK, Tumwesigye NM, Gamzell-Danielsson K Prevalence and factors associated with sexually transmitted infections among HIV positive women opting for intrauterine contraception. PLoS One. 2015;10(4):e0122400.

14. Sweet T, Welles SL. Associations of sexual identity or same-sex behaviors with history of childhood sexual abuse and HIV/STI risk in the United States. J Acquir Immune Defic Syndr. 2012;59(4):400-8.

15. Basera T, Takuva S, Muloongo K, Tshuma N, Nyasulu P. Prevalence and Risk Factors for Self-reported Sexually Transmitted Infections among Adults in the Diepsloot Informal Settlement, Johannesburg, South Africa. J AIDS Clin Res. 2016;7(1):1-5. https:/www.omicsonline.org/open-access/prevalence-and-risk-factors-forselfreported-sexually-transmittedinfections-among-adults-in-the-diepsloot-informalsettlementjohan-2155-6113-1000539.pdf.

16. Johnson LF, Dorrington RE, Bradshaw D, Coetzee DJ. The role of sexually transmitted infections in the evolution of the South African HIV epidemic. Trop Med Int Health. 2012;17(2):161-8.

17. Clifford G, Franceschi S, Diaz M, Munoz N, Villa LL. Chapter 3: HPV typedistribution in women with and without cervical neoplastic diseases. Vaccine. 2006;24 Suppl 3:S3/26-34.

18. Lindstrand A, Bergstrom S, Bugalho A, Zanconato G, Helgesson AM, Hederstedt B. Prevalence of syphilis infection in Mozambican women with second trimester miscarriage and women attending antenatal care in second trimester. Genitourin Med. 1993;69(6):431-3.

19. Moodley P, Sturm AW. Sexually transmitted infections, adverse pregnancy outcome and neonatal infection. Semin Neonatol. 2000;5(3):255-69.

20. Almonte M, Albero G, Molano M, Carcamo C, Garcia PJ, Perez G. Risk factors for human papillomavirus exposure and co-factors for cervical cancer in Latin America and the Caribbean. Vaccine. 2008;26 Suppl 11:L16-36.

21. Appleby P, Beral V, Berrington de Gonzalez A, Colin D, Franceschi S, Goodhill A, Green J, Peto J, Plummer M, Sweetland S. Cervical cancer and hormonal contraceptives: collaborative reanalysis of individual data for 16,573 women with cervical cancer and 35,509 women without cervical cancer from 24 epidemiological studies. Lancet. 2007;370:1609-21. 
22. Laumann EO, Youm Y. Racial/ethnic group differences in the prevalence of sexually transmitted diseases in the United States: a network explanation. Sex Transm Dis. 1999;26(5):250-61.

23. Gindi RM, Erbelding EJ, Page KR. Sexually transmitted infection prevalence and behavioral risk factors among Latino and non-Latino patients attending the Baltimore City STD clinics. Sex Transm Dis. 2010;37(3):191-6.

24. Niyazi M, Husaiyin S, Han L, Mamat H, Husaiyin K, Wang L. Prevalence of and risk factors for high-risk human papillomavirus infection: a population-based study from Hetian, Xinjiang, China. Bosn J Basic Med Sci. 2016;16(1):46-51.

25. Ragin CC, Watt A, Markovic N, Bunker CH, Edwards RP, Eckstein S, Fletcher $\mathrm{H}$, Garwood D, Gollin SM, Jackson M, et al. Comparisons of high-risk cervical HPV infections in Caribbean and US populations. Infect Agent Cancer. 2009;4 Suppl 1:S9.

26. Chadambuka A, Chimusoro A, Maradzika JC, Tshimanga M, Gombe NT, Shambira G. Factors associated with contracting sexually transmitted infections among patients in Zvishavane urban, Zimbabwe; 2007. Afr Health Sci. 2011;11(4):535-42.

27. Cordova D, Huang S, Lally M, Estrada Y, Prado G. Do parent-adolescent discrepancies in family functioning increase the risk of Hispanic adolescent HIV risk behaviors? Fam Process. 2014;53(2):348-63.

28. Ragnarsson A, Ekstrom AM, Carter J, llako F, Lukhwaro A, Marrone G, Thorson A Sexual risk taking among patients on antiretroviral therapy in an urban informal settlement in Kenya: a cross-sectional survey. J Int AIDS Soc. 2011;14:20.

29. UNAIDS. HIV and AIDS estimates (2015): Swaziland. Geneva: UNAIDS; 2015.

30. Cepheid. GeneXpert. Xpert ${ }^{\oplus}$ CT/NG, vol. GXCT/NG-CE-10. GXCT/NG-CE-120. Sunnyvale: Cepheid; 2014.

31. Cepheid. GeneXpert. Xpert ${ }^{\circledast}$ TV, vol. GXTV-CE-10. Sunnyvale: Cepheid; 2014

32. Atlas Medical. RPR SYPHILIS CARD TEST. Cambridge: Atlas Medical; 2014.

33. Omega Diagnostic. Treponema Pallidum Haemagglutination (TPHA) Test Cells, vol. MSDS 0043. Scotland: Omega Diagnostic; 2004.

34. Cepheid. GeneXpert. Xpert HPV. GXHPV-CE-10th ed. Sunnyvale: Cepheid; 2014

35. Alere Determine ${ }^{T M} \mathrm{HIV}-1 / 2 \mathrm{Ag} / \mathrm{Ab}$ Combo [http://www.alere.com/en/home/ product-details/determine-1-2-ag-ab-combo.html]. Accessed 2 Dec 2015.

36. Trinity Biotech PLC. Uni-Gold ${ }^{\mathrm{TM}}$ Recombigen ${ }^{\oplus} H \mathrm{IV}$. Bray: Trinity Biotech PLC; 2014.

37. The Kingdom of Swaziland Gorvernment and UNFPA. Swaziland Population Projections 2007-2030. In. Edited by Office CS; 2007

38. Ginindza TG, Dlamini $X$, Almonte M, Herrero R, Jolly PE, Tsoka-Gwegweni JM, Weiderpass E, Broutet N, Sartorius B. Prevalence of and associated risk factors for high risk human papillomavirus among sexually active women, Swaziland. PloS one. 2017;12(1):e0170189.

39. Sternberg ED, Lefevre T, Rawstern AH, de Roode JC. A virulent parasite can provide protection against a lethal parasitoid. Infect Genet Evol. 2011;11(2):399-406.

40. Pedersen $A B$, Fenton $A$. Emphasizing the ecology in parasite community ecology. Trends Ecol Evol. 2007;22(3):133-9.

41. Abbai NS, Wand H, Ramjee G. Sexually transmitted infections in women participating in a biomedical intervention trial in Durban: prevalence, coinfections, and risk factors. J Sex Transm Dis. 2013;2013:358402.

42. Naidoo S, Wand H, Abbai NS, Ramjee G. High prevalence and incidence of sexually transmitted infections among women living in Kwazulu-Natal, South Africa. AIDS Res Ther. 2014;11:31.

43. Tyndall MW, Kidula N, Sande J, Ombette J, Temmerman M. Predicting Neisseria gonorrhoeae and Chlamydia trachomatis infection using risk scores, physical examination, microscopy, and leukocyte esterase urine dipsticks among asymptomatic women attending a family planning clinic in Kenya. Sex Transm Dis. 1999;26(8):476-82.

44. Newman L, Rowley J, Vander Hoorn S, Wijesooriya NS, Unemo M, Low N, Stevens G, Gottlieb S, Kiarie J, Temmerman M. Global estimates of the prevalence and incidence of four curable sexually transmitted infections in 2012 based on systematic review and global reporting. PLoS One. 2015;10(12):e0143304.

45. The Kingdom of Swaziland, Ministry of Health. The National HIV serosurveillance. Mbabane: Swaziland National AIDS Programme; 2004

46. The Kingdom of Swaziland, Ministry of Health. National HIV Serosurveillance. Mbabane: Swaziland National AIDS Programme; 2003.

47. The Kindom of Swaziland, Ministry of Health. 11th Sentinel Survellance. Mbabane: Swaziland National AIDS Programme; 2008.

48. Francis SC, Ao TT, Vanobberghen FM, Chilongani J, Hashim R, Andreasen A, Watson-Jones D, Changalucha J, Kapiga S, Hayes RJ. Epidemiology of curable sexually transmitted infections among women at increased risk for HIV in northwestern Tanzania: inadequacy of syndromic management. PLoS One. 2014;9(7):e101221

49. Vuylsteke B. Current status of syndromic management of sexually transmitted infections in developing countries. Sex Transm Infect. 2004;80(5):333-4.
50. Bicego GT, Nkambule R, Peterson I, Reed J, Donnell D, Ginindza H, Duong YT, Patel H, Bock N, Philip N, et al. Recent patterns in population-based HIV prevalence in Swaziland. PLoS One. 2013;8(10):e77101.

51. The Kingdom of Swaziland, Ministry of Health. The 12th round of national HV serosurveillance in Swaziland. Mbabane: Swaziland National AIDS Programme; 2010.

52. Oliveira FA, Pfleger V, Lang K, Heukelbach J, Miralles I, Fraga F, Sousa AQ, StofflerMeilicke M, Ignatius R, Kerr LF, et al. Sexually transmitted infections, bacterial vaginosis, and candidiasis in women of reproductive age in rural Northeast Brazil: a population-based study. Mem Inst Oswaldo Cruz. 2007;102(6):751-6.

53. N WC, A S. Associated risk factors of STIs and multiple sexual relationships among youths in Malawi. PLoS One. 2015;10(8):e0134286.

54. de Lima YA, Turchi MD, Fonseca ZC, Garcia FL, Cardoso FA DBe, da Guarda Reis MN, de Britto Guimaraes EM, Alves RR, Carvalho NR, de Fatima Costa Alves M. Sexually transmitted bacterial infections among young women in central Western Brazil. Int J Infect Dis. 2014;25:16-21.

55. Nyarko C, Unson C, Koduah M, Nyarko P, Galley J. Risk Factors Of SexuallyTransmitted Infections (Stis) Among Men And Women In A Mining Community In Western Ghana: A Study Of Lifetime Occurrence. Int J Of Scie \& Tech Res. 2014 3(12):1-10.

56. de Lima SV, de Mesquita AM, Cavalcante FG, Silva ZP, Hora V, Diedrich T, de Carvalho SP, de Melo PG, Dacal AR, de Carvalho EM, et al. Sexually transmitted infections in a female population in rural north-east Brazil: prevalence, morbidity and risk factors. Trop Med Int Health. 2003;8(7):595-603.

57. Arbabi M, Fakhrieh Z, Delavari $M$, Abdoli A. Prevalence of Trichomonas vaginalis infection in Kashan city, Iran (2012-2013). Iran J Reprod Med. 2014;12(7):507-12.

58. Singa B, Glick SN, Bock N, Walson J, Chaba L, Odek J, McClelland RS, Djomand G, Gao H, John-Stewart G. Sexually transmitted infections among HIV-infected adults in HIV care programs in Kenya: a national sample of HIV clinics. Sex Transm Dis. 2013;40(2):148-53.

59. Muula AS. HIV infection and AIDS among young women in South Africa. Croat Med J. 2008;49(3):423-35.

60. Crucitti T, Jespers V, Mulenga C, Khondowe S, Vandepitte J, Buve A. Nonsexual transmission of Trichomonas vaginalis in adolescent girls attending school in Ndola, Zambia. PloS one. 2011;6(1):e16310.

61. Ramjee G, Daniels B. Women and HIV in Sub-Saharan Africa. AIDS Res Ther. 2013;10(1):30.

62. Ahmed S, Lutalo T, Wawer M, Serwadda D, Sewankambo NK, Nalugoda F, Makumbi F, Wabwire-Mangen F, Kiwanuka N, Kigozi G, et al. HIV incidence and sexually transmitted disease prevalence associated with condom use: a population study in Rakai, Uganda. AIDS (London, England). 2001;15(16):2171-9.

63. Ali Abdulai M, Baiden F, Afari-Asiedu S, Gyabaa-Febir L, Adjei KK, Mahama E, Tawiah-Agyemang C, Newton SK, Asante KP, Owusu-Agyei S. The risk of sexually transmitted infection and its influence on condom use among pregnant women in the Kintampo North municipality of Ghana. J Sex Transm Dis. 2017;2017:8642685

64. Samarawickrema NA, Tabrizi SN, Young E, Gunawardena P, Garland SM. Prevalence of trichomonas vaginalis, Chlamydia trachomatis, neisseria gonorrhoeae and human papillomavirus in a sexual health clinic setting in urban Sri Lanka. Int J STD AIDS. 2015;26(10):733-9.

65. Vielot N, Hudgens MG, Mugo N, Chitwa M, Kimani J, Smith J. The role of Chlamydia trachomatis in high-risk human papillomavirus persistence among female Sex workers in Nairobi, Kenya. Sex Transm Dis. 2015;42(6):305-11.

66. Wohlmeister D, Vianna DR, Helfer VE, Gimenes F, Consolaro ME, Barcellos RB, Rossetti ML, Calil LN, Buffon A, Pilger DA. Association of human papillomavirus and Chlamydia trachomatis with intraepithelial alterations in cervix samples. Mem Inst Oswaldo Cruz. 2016;111(2):106-13.

67. Giuliano AR, Botha MH, Zeier M, Abrahamsen ME, Glashoff RH, van der Laan LE, Papenfuss M, Engelbrecht S, van der Loeff MF S, Sudenga SL, et al. High HIV, HPV, and STI prevalence among young Western Cape, South African women: EVRI HIV prevention preparedness trial. J Acquir Immune Defic Syndr. 2015;68(2):227-35.

68. Lissouba P, Van de Perre P, Auvert B. Association of genital human papillomavirus infection with HIV acquisition: a systematic review and metaanalysis. Sex Transm Infect. 2013;89(5):350-6.

69. Rositch AF, Gravitt PE, Smith JS. Growing evidence that HPV infection is associated with an increase in HIV acquisition: exploring the issue of HPV vaccination. Sex Transm Infect. 2013:89(5):357.

70. United Nation GA. Transforming our world: the 2030 agenda for sustainable development, vol. A/RES/70/1. New York: United Nation GA; 2015.

71. The Kingdom of Swaziland, Ministry of Health. National guidelines for HIV testing and counseling. Mbabane: The Kingdom of Swaziland, Ministry of Health; 2014. 